\title{
PENANAMAN NILAI-NILAI AKHLAK PADA ANAK TUNAGRAHITA DALAM PENDIDIKAN VOKASIONAL \\ Studi Deskriptif Kualitatif di Balai Rehabilitasi Sosial Disgranda "Raharjo" Sragen
}

\author{
Etik Kurniawati \\ Sekolah Tinggi Ilmu Tarbiyah (STIT) Madina Sragen \\ Email:etikkurniawati46@gmail.com
}

\begin{abstract}
The importance of an education includes the moral education for all citizens. No exception for children with mental disabilities or mental disabilities. Such shortcomings or limitations do not become an obstacle for the child's tunagrahita in accepting his right namely in the case of education. In reality, education for children with tunagrabita can not be equated with normal children in general. Not that the deficiency of the child's tunagrabita can not be educated and directed to good morals. The focus of this research are: (1) How is the method used in inculcating moral values for the child's tunagrahita through vocational education in Social Rehabilitation Hall Disgranda "Raharjo" Sragen? (2) What morality is formed through the cultivation of vocational education at the Social Rehabilitation Hall Disgranda "Raharjo" Sragen ?. The purpose of his research is to know the method used and morality that
\end{abstract}




\title{
Chamim Tohari
}

is formed for the children through the education of vocational education at the Social Rehabilitation Hall Disgranda "Raharjo" Sragen. Research on the cultivation of moral values in children tunagrahita in vocational education uses a qualitative approach by using descriptive analysis method. The data were collected using observation, interview, and documentation techniques. Data analysis techniques through data reduction, data presentation and conclusion. Checking the validity of data is done by extending the presence of researchers, continuous observation and meticulous, and triangulation techniques using various sources, methods and theories. The results of this research are: (1) the method used in Barehsos Disgranda "Raharjo" Sragen is: exemplary method, method of habituation, method of advice, method of supervision, method of gift giving, and punishment method. (2) morality is formed morals to self in the form of independence of life, responsibility, discipline, cooperation, and able to social interaction with the environment.

Keyword: Caracter Building, Anak Tunagrabita, Vocational Education

\begin{abstract}
Abstrak
Pentingnya suatu pendidikantermasuk di dalamnya adalah pendidikan akblak bagi selurub warga negara. Tidak terkecuali bagi anak tunagrabita yang memiliki kekurangan atau keterbatasan dalam hal mental. Kekurangan atau keterbatasan tersebut tidak menjadi suatu penghalang bagi anak tunagrahita di dalam menerima haknya yaitu dalam hal pendidikan. Dalam kenyatannya pendidikan bagi anake tunagrahita tidak dapat disamakan dengan anak normal pada umumnya.Bukan berarti dengan kekurangan yang dimiliki anake tunagrabita tidak bisa dididik dan diarabkan untuk berakblak baik. Fokus Penelitian ini adalah: (1) Bagaimana metode yang digunakan dalam menanamkan nilai-nilai akblak bagi anak tunagrabita melalui pendidikan vokasional di Balai Rehabilitasi Sosial Disgranda "Raharjo" Sragen? (2) Akblak apa yang dibentukmelalui penanaman pendidikan vokasional di Balai Rehabilitasi Sosial Disgranda "Raharjo" Sragen?. Adapun tujuan penelitiannya untuk mengetabui metode yang digunakan dan akblak yang dibentuk bagi anak tuna grabitamelalui pendidikan vokasional di Balai Rehabilitasi Sosial Disgranda"Raharjo" Sragen.
\end{abstract}


Hukuki Aile Kararnamesi: Reformasi dan Konstitusionalisasi.....

Penelitian tentang penanaman nilai akblak pada anak tunagrabita dalam pendidikan vokasional ini menggunakan pendekatan kualitatif dengan menggunakan metode deskriptif analisis.Pengumpulan data dilakukan dengan menggunakan teknik observasi, wawancara, dan dokumentasi.Teknik analisis data melalui reduksi data, penyajian data dan penarikan kesimpulan.Pengecekan keabsahan data dilakukan dengan perpanjangan kehadiran peneliti, pengamatan terus menerus dan cermat, serta teknik triangulasi dengan menggunakan berbagai sumber, metode dan teori. Hasil penelitian dalam penelitian ini adalah: (1) metode yang digunakan di Barehsos Disgranda "Raharjo" Sragen adalah: metode keteladanan, metode pembiasaan, metode nasihat, metode pengawasan, metode pemberian hadiah, dan metode hukuman. (2) akblak yang dibentuk adalah akblak kepada diri sendiri yang berupa kemandirian hidup, tanggung jawab, disiplin, kerja sama, dan mampu berinterkasi sosial dengan lingkungan.

Keyword: Penanaman Akhlak, Anak Tunagrabita, Pendidikan Vokasional

\section{A. Pendahuluan}

Pendidikan merupakan usaha sadar yang dilakukan oleh keluarga, masyarakat dan pemerintah, melalui kegiatan bimbingan, pembelajaran, dan latihan, yang berlangsung di sekolah dan di luar sekolah sepanjang hayat, untuk mempersiapkan peserta didik agar dapat memainkan peranan dalam berbagai lingkungan hidup secara tepat di masa yang akan datang. Dalam literatur lain, pendidikan adalah semua perbuatan atau semua usaha dari generasi tua untuk mengalihkan (melimpahkan) pengetahuannya, pengalamanya, kecakapan serta keterampilannya kepada generasimuda, sebagai usaha untuk menyiapkan mereka agar dapat memenuhi fungsihidupnya, baik jasmaniah maupun rohaniah. ${ }^{1}$

\section{Zuhairini, Filsafat didikan Islam, (Jakarta: .Bumi Aksara, 1992), hlm. 92}


Kebutuhan akan pendidikan merupakan hal yang tidak bisa dipungkiri, bahkan semua itu merupakan hak semua warga Negara. Di dalam UUD 1945 pasal 31 ayat (1) secara tegas disebutkan bahwa; "Tiap-tiap warga negara berhak mendapat pembelajaran". Maka dari itu negara harus memberikan pembelajaran kepada semua warga negara tanpa terkecuali, termasuk juga warga negara yang memiliki keterbatasan baik fisik, mental, ekonomi dan sebagainya. Yang mana amanat akan hak atas pendidikan bagi penyandang kelainan telah ditetapkan dalam undang-undang nomor 20 tahun 2003 tentang sistem pendidikan nasional pasal 32 disebutkan bahwa: "pendidikan khusus (pendidikan luar biasa) merupakan pendidikan bagi peserta didik yang memiliki tingkat kesulitan dalam mengikuti prosespembelajaran karena kelainan fisik, emosional, mental, sosial"'.2

Tujuan pendidikan nasional dinyatakan dalam UU RI nomor 20 Tahun 2003 pasal 3 bertujuan untuk berkembangnya potensi peserta didik agar menjadi manusia yang beriman dan bertakwa kepada Tuhan Yang Maha Esa, berakhlak mulia, sehat, berilmu, cakap, kreatif mandiri, dan menjadi wargaNegara yang demokratis serta bertanggung jawab. ${ }^{3}$ Untuk mewujudkan tujuan pendidikan di atas, salah satunya dapat dicapai melalui pendidikanakhlak yang di dalamnya membahas mengenai keimanan dan ketaqwaan kepada Tuhan Yang Maha Esa, akhlak mulia, sehat, berilmu, cakap, kreatif mandiri, dan menjadi warga negara yang demokratis serta bertanggung jawab.

Akhlak adalah suatu bentuk (karakter) yang kuat di dalam jiwa yang darinya muncul perbuatan yang bersifat iradiyah ikhtiyariyah (kehendak pilihan) berupa baik atau buruk, indah atau jelek, sesuai pembawaanya, ia menerima pengaruh pendidikan yang baik dan yang buruk. ${ }^{4}$ Akhlak merupakan sikap yang

${ }^{2}$ Mohammad Efendi, Pengantar Psikopedagogik Anak Berkelainan, (Jakarta: PT Bumi Aksara, 2006),hlm. 1

${ }^{3}$ M. Sukarjo, Ukim Komarudin, Landasan Pendidikan Konsep dan Aplika inya, (Jakarta: Rajawali Pers, 2009), hlm. 14.

${ }^{4}$ Amru Khalid, Semulia Akhlak Nabi. (Solo : Aqwam, 2006), hlm. 22 
Hukuki Aile Kararnamesi: Reformasi dan Konstitusionalisasi.....

telah ada pada diri seseorang dan dilakukan diluar kesadaran. Lingkungan juga berpengaruh terhadap perkembangan pola pikir dan akhlak anak.

Pendidikan akhlak merupakan bagian integral dari sistem pendidikan nasional, dimana suatu pendidikan hendaklah dapat menjangkau dan dapat diakses dan dinikmati oleh seluruh lapisan pendidikan, yang tidak memandang akan adanya suatu pengecualian baik dalam hal keterbatasan sosial, fisik maupun ekonomi, dan dalam setrata tertentu.

Manusia merupakan makhluk Allah yang paling sempurna karena dianugerahi akal yang dapat digunakan untuk berfikir. Karunia akal itulah yang menjadi pembeda antara manusia dengan makhluk lainnya jika digunakan secara optimal.Lalu bagaimana dengan manusia yang di beri kekurangan fisik, di mana organ terpentingnya mengalami kelainan.Di dalam dunia pendidikan, manusia yang mengalami kelainanatau keterbelakangan mental ini disebut tunagrahita.Artinya, meski berada dalam keterbatasan secara mental, bukan berarti anak tunagrahita tidak bisa dididik dan diarahkan untuk berakhlak baik.

Dengan adanya keterbatasan yang dimiliki oleh peserta didik, apalagi menyangkut keterbatasan dalam hal mental, tentunya dalam memberikan pembelajaran harus menggunakan metode atau caracara yang khusus agar tujuan dari proses pendidikan yang dilakukan dapat tercapai dengan baik. Adapun metode atau cara tersebut hendaklah disesuaikan dengan kondisi dan kemampuan peserta didik yang dihadapi.Anak-anak tunagrahita ini akan mengalami permasalahan atau problem dalam hidup di dunia, karena intelegensi mereka dibawah rata-rata anak normal.

Penanaman agama dimaksudkan untuk membentuk peserta didik menjadi manusia yang beriman dan bertaqwa kepada Tuhan Yang Maha Esa dan berakhlak mulia serta peningkatan potensi spiritual.Akhlak mulia mencakup etika, budi pekerti, dan moral sebagai perwujudan dari pendidikan agama.Peningkatan potensi spiritual mencakup pengenalan, pemahaman, dan penanaman 
nilai-nilai keagamaan, serta pengamalan nilai-nilai tersebut dalam kehidupan individual ataupun kolektif kemasyarakatan. Peningkatan potensi spiritual tersebut pada akhirnya bertujuan pada optimalisasi berbagai potensi yang dimiliki manusia yang aktualisasinya mencerminkan harkat dan martabatnya sebagai makhluk Tuhan.

Pengelolaan pendidikan vokasional bagi anak tunagrahita ini tidak mudah, karena harus dikaitkan dengan potensi masing-masing anak yang bervariasi dan bersifat individual. Mereka memerlukan bimbingan atau layanan secara khusus untuk membantunya mempelajari segala sesuatu, baik dalam hal pendidikan maupun kegiatan hidup sehari-hari (Activity Of Daily Living), namun bukan harapan yang terlalu muluk jika anak tunagrahita dapat memiliki keterampilan hidup (life skill) sehingga anak lebih mandiri dan tidak bergantung pada orang lain.

Menanamkan akhlak dalam pendidikan vokasional sangat penting untuk mengarahkan anak tunagrahita ke pembentukan akhlak yang baik, yaitu bertujuan agar anak jujur dalam tata bicara, mandiri dalam setiap akivitas sehari-harisesuai dengan akhlakul karimah, bertanggug jawab dalam mengurus dirinya sendiri serta memiliki keahlian di bidang keterampilan sesuai dengan kemampuannya sehingga ketika anak tunagrahita terjun ke masyarakat anak sudah siap kerja.

\section{B. Pembahasan}

\section{Penanaman Nilai-Nilai Akhlak}

Pengertian akhlak secaraetimologi berasal dan kata khuluq dan jamaknya akhlak yang berarti budi pekerti, etika, moral. ${ }^{5} \mathrm{~A} 1$ Ghazali menjelaskan bahwa khulq adalah suatu kondisi (hai'ah) dalam jiwa (nafs) yang suci (rasikhah), dan dari kondisi itu tumbuh

${ }^{5}$ Muhaimin, dkk.Studi Islam dalam Ragam Dimensi dan Pendekatan. (Jakarta : Kencana Prenada Media Group, 2005), hlm. 262 
suatu aktivitas yang mudah dan gampang tanpa memerlukan pemikiran dan pertimbangan terlebih dahulu. ${ }^{6}$

Menurut Sidi Gazalba ${ }^{7}$, tindakan yang mengandung nilai akhlak itu ialah tindakan yang sadar atau yang disengaja. Tidak semua tindakan manusia dilakukannya dengan sadar atau sengaja. Jadi akhlak hanya menyangkut laku perbuatan manusia. Dan tidak pula segala laku perbuatannya itu mengandung nilai baik buruk, melainkan tindakan yang dilakukan dengan sadar dan mengetahui apa yang diperbuatnya.

Nilai-nilai akhlak merupakan bagian dari nilai-nilai Islam yang terwujud dalam kenyataan pengalaman rohani dan jasmani. Nilai-nilai keislaman merupakan tingkatan integritas kepribadian yang mencapai tingkat budi (insan kamil). "Akhlak” adalah ilmu pengetahuan yang memberikan pengertian tentang baik dan buruk, ilmu yang mengajarkan manusia dan menyatakan tujuan mereka yang terakhir dan seluruh usaha dan pekerjaan mereka.

Akhlak adalah sikap yang melahirkan perbuatan dan tingkah laku manusia.Karena itu, selain dengan akidah, akhlak tidak dapat dipisahkan dengan syari'ah. Karena syari'ah mencakup segala aspek kehidupan manusia, maka ruang lingkup akhlakpun dalam islam meliputi segala aktivitas aspek kehidupan manusia, oleh karena itu, ruang lingkup akhlak sama dengan ruang lingkup ajaran islam. Secara garis besar Yunahar Ilyas ${ }^{8}$, membagi akhlak menjadi beberapa yakni:

a) Akhlak kepada Allah

b) Akhlak kepada sesama manusia, meliputi akhlak kepada Rasulullah SAW, orangtua, diri sendiri dan orang lain. Akhlak terhadap rasulullah, Akhlak terhadap orangtua, Akhlak terhadap diri sendiri, Akhlak kepada orang lain.

c) Akhlak terhadap lingkungan sekitar

${ }^{6}$ Al-Ghazali.Ihya' Ulumuddin Jilid IV.(Faisan : Jakarta Selatan, 1989)

${ }^{7}$ Sidi Gazalba, Sistematika Filsafat (Jakarta: Bulan Bintang, 1981),hlm. 539

${ }^{8}$ Yunahar Ilyas. Kuliah Akhlak. (Yogyakarta : Pustaka Pelajar Offset, 1999), hlm, 82-90 
Metode pendidikan akhlak menurut Imam al-Ghazali yang dikutip Abudin Nata'misalnya mengatakan sebagai berikut:

"Seandainya akblak itu tidak dapat menerima perubahan, maka batallah fungsi wasiat, nasibat dan pendidikan dan tidak ada pula fungsinya hadits nabi yang mengatakan "perbaikilah akblak kamu sekalian".

Mendidik memerlukan berbagai metode yang tepat agar diperoleh hasil yang optimal. Metode pendidikan akhlak menurut Abdullah Nasih Ulwan dikutip dalam Nur Khayati ${ }^{10}$ adalah sebagai berikut:

1. Metode Keteladanan

2. Metode Pembiasaan

3. Metode Pengawasan

4. Metode Nasihat dan Peringatan

5. Metode Targhib (Hadiah) dan Tarhib (Hukuman)

Jadi, menanamkan nilai-nilai akhlak adalah menanamkan sikap atau perilaku yang mendorong seseorang untuk melakukan perbuatan tanpa melalui pertimbangan dan pemikiran (secara spontan).Dalam menanamkan nilai-nilai akhlak membutuhkan rangsangan yang tepat sehingga dapat terbentuk secara baik dalam penerapan dan perkembangannya, dimana ada beberapa faktor baik internal maupun eksternal yang berpengaruhdalam mendorong terbentuknya akhlak yang baik, terutama akhlak terhadap diri sendiri.

\section{Anak Tunagrahita}

Istilah tunagrahita berasal dari bahasa sansekerta tuna yang artinya rugi, kurang, dan grahita artinya berfikir.Tunagrahita dipakai sebagai istilah resmi di Indonesia sejak dikeluarkan

${ }^{9}$ Abuddin Nata. Akhlak Tasawuf. (Jakarta : Rajawali Pers, 2012), hlm. 112

${ }^{10}$ Nur Khayati. 2013. Pendidikan Akhlak pada anak tunagrahita di SDLB Negeri Sukoharjo, Margorejo, Pati.(IAINSurakarta: PAI FTB, 2013), hlm. 29-30 
peraturan pemerintah tentang pendidikan luar biasa No 72 tahun $1991 .{ }^{11}$

Sedangkan definisi tunagrahita secara luas, ada banyak pakar yang memberikan pengertian. Tetapi dari sekian definisi tersebut, penulis menganggapbahwa definisi yangdikemukakan olehAmericanAssociation Mental Deficienci $(A A M D)$ yang kemudian pada tahun 1992berubah namanya menjadiAmerican Association of Mental Retardation( $A A M R)$ sudah mampu merangkum keseluruhan makna yaitu sebagaiberikut: ${ }^{12}$

"Mental retardation refers to substantial limitation in presentfunctioning by significantly subaverage intellectual functioning, existing concurrently with related limitations in two or more of the following applicable adative skill areas: communication, self care, home living, social skill, community use, self-direction, healt and safety, functional academics, leisure, and work. Mental retardation manifest before age 18"

Maksud dari kutipan di atas bahwa mental retardasi merujuk padaketerbatasan fungsi intelektual umum dan keterbatasan pada keterampilanadaptif, keterampilan adaptif mencakup area komunikasi, merawat diri,home living, keterampilan sosial, bermasyarakat, mengontrol diri,funcsional akademik, waktu luang dan kerja. Ketunagrahitaan munculsebelum usia 18 tahun.

Sedangkan pendapat Bratarana dalam M. Effendi ${ }^{13}$, menjelaskan seseorang dikategorikan berkelainan mental subnormal atau tunagrahita, jika ia memiliki tingkat kecerdasan yang sedemikian rendahnya (dibawah normal), sehingga untuk

${ }^{11}$ Mumpuniarti,Pendekatan Pembelajaran Bagi Anak Hambatan Mental,(Yogyakarta: Kanwa Publisher,2007), hlm. 25

${ }^{12}$ Heri Purwanto, Diktat Ortopedagogik Umum, (Yogyakarta : PLB IKIP, 1998), hlm. 17

${ }^{13}$ M. Effendi. Pengantar Psikopedagogik Anak Berkelainan. (Jakarta : PT. Bumi Aksara, 2006), hlm. 88 
meniti tugas perkembangannya memerlukan bantuan atau layanan secara spesifik, termasuk dalam program pendidikannya.

Jadi, secara umum anak tunagrahita dapat diartikan sebagai anak yang memiliki tingkat kecerdasan dibawah anak-anak normal yang sebaya sehingga dalam pendidikanya memerlukan penanganan khusus.

Pada umumnya pengelompokan anak tunagrahita tersebut berdasarkan pada taraf intelegensinya, yang terdiri dari terbelakang ringan, sedang, dan berat. ${ }^{14}$ Adapun klasifikasi anak tunagrahita ada beberapa pengelompokan, yaitu:

1. Tunagrahita Ringan

Tunagrahita ringan disebut juga moron atau debil.Dalam kelompok ini anak tunagrahita memiliki IQ antara 68-52 menurut Binet, sedangkan menurut Skala Weschler memiliki IQ 69-55. Mereka masih dapat belajar membaca, menulis, dan berhitung sederhana.

\section{Tunagrahita Sedang}

Anak tunagrahita sedang disebut juga imbesil.Mereka memiliki IQ 51-36 pada skala binet dan 54-40 menurut skala weschler (WISC).Mereka dapat dididik mengurus diri sendiri, melindungi diri sendiri dari bahaya, berjalan di jalan raya, berlindung dari hujan dan lain sebagainya.

3. Tunagrahita Berat

Anak tunagrahita berat sering disebut idiot.Kelompok ini masih dapat di bedakan lagi antara anak tunagrahita berat dan anak tunagrahita sangat berat.Tunagrahita berat (severe) memiliki IQ antara 32-20 menurut Skala Binet dan antara 39-25menurut skala Weschler (WISC). Tunagrahita sangat berat (Profound) memiliki IQ di bawah 19 menurut Skala Binet dan IQ di bawah 24 menurut Skala Weschler (WISC).

${ }^{14}$ H.T. Sutjihati Somantri, Psikologi Anak Luar Biasa, (DEPDIKBUD: Dirjen Pendidikan Tinggi Proyek Pendidikan Tenaga Guru, 1996), hlm. 84 
Hukuki Aile Kararnamesi: Reformasi dan Konstitusionalisasi.....

\section{Pendidikan Vokasional}

Vocational Skill disebut juga dengan kecakapan kejuruan. Artinya kecakapan ini tidak hanya untuk menyiapkan tenaga terampil dan kreatif (vocational), tetapi juga menyiapkan anak didik yang mampu mengatasi dan memecahkan permasalahan kehidupan yang dihadapi dengan cara lebih baik dan lebih tepat, krena memiliki latar belakang keilmuan. ${ }^{15}$

Pada perkembangannya substansi vocational skill lebih menekankan pada segi kemampuan professional anak didik dalam menghadapi tantangan kehidupan ditengah-tengah masyarakat. Pencapaian untuk meningkatkan keterampilan dilakukan sesuai dengan perkembangan masyarakat dalam rangka membangun karier pada masa depan.

Dengan keterampilan yang ditekuni, anak didik mempunyai kesempatan untuk mengoptimalisasikan segenap potensi yang ada dalam kehidupan nyata, sehingga potensi yang berupa keterampilan dapat dikembangkan secara integral untuk memiliki kecakapan yang luas, mandiri, tanggung jawab, dan mampu mengatasi kesulitan-kesulitan dalam hidup.

Strategi meningkatkan mental vocational skill ${ }^{16}$, dijelaskan sebagai berikut:

a. Memberikan sosialisasi akan signifikansi mental vocational

b. Melatih kemandirian dalam menghadapi tantangan kehidupan

c. Memberikan bekal pengetahuan yang cukup

d. Memberikan pelatihan dan pengembangan dalam memasuki dunia kerja

${ }^{15}$ M. Takdir Illahi. Pembelajaran Discovery Strategy \& Mental Voc tional Skill. (Yogyakarta: Diva Press, 2012), hlm. 132

${ }^{16}$ M. Takdir Illahi. Pembelajaran Discovery Strategy \& Mental Voc tional Skill. (Yogyakarta: Diva Press, 2012), hlm. 136-143 
e. Menyediakan sarana dan prasarana yang dibutuhkan dalam meningkatkan mental vocational skill

f. Meningkatkan kinerja suatu keterampilan

Jadi, pendidikan vokasional penting untuk membekali keterampilan diri anak supaya menjadi berkualitas, mandiri, tanggung jawab, dan memiliki kemampuan secara mental ataupun fisik dalam memasuki dunia kerja, dapat menghasilkan individu yang kreatif dan produktif.

\section{Perencanaan Penerapan Nilai-nilai Akhlak Melalui Pendidikan Vokasional}

Pendidikan vokasional yang diajarkan di Barehsos "Disgranda" Sragen ada berbagai macam.Yang menjadi fokus dalam penelitian ini adalah bimbingan activity daily living (ADL). Silabus dan RPP tidak menjadi tuntutan dalam pelaksanaan kegiatan tersebut, dan tes assessment diberikan kepada setiap anak sebelum pelaksanaan pendidikan vokasional. Instrumen yang digunakan dalam tes tersebut diantaranya:

a. Grip

Berfungsi untuk mengetahui potensi, bakat minat, kemauan anak, melalui kekuatan jari dan genggaman tangan, ukuran minimal 20 kilogram untuk anak tunagrahita.

b. Block kohs

Alat untuk mengetahui bentuk, pola dan warna.

c. Sisip ring

Alat untuk mengetahui koordinasi antara jari, mata dan pikiran.

d. Form

Alat untuk mengetahui model, bentuk, menyusun ketepatan. 
e. Puzzle

Alat untuk mengenalkan dan menjelaskan nama, bentuk, serta fungsi benda melalui media demonstrasi.

f. Format penilaian

Panduan penilaian untuk mengetahui hasil yang diperoleh setelah tes. Format penilaian ini juga meliputi tes kematangan sosial untuk mengetahui seberapa besar kemampuan perkembangan adaptasi anak, yang akan berpengaruh pada besar IQ anak.

Pembagian IQ sebagai berikut:

1) IQ $90>\%=$ kategori normal

2) IQ $90-71 \%=$ kategori bodoh

3) IQ $71-50 \%=$ kategori debil

4) IQ 50-30\%= kategori embisil

5) IQ dibawah $30 \%=$ kategori berat

Berikut wawancara dengan salah satu peksos yang menguatkan hasil temuan tersebut: "Pada awalnya, sebelum anak masuk ke kelompok vokasional, terlebih dahulu di tes assessment untuk mengukur kemampuan anak yang dimiliki. Tes assessment tersebut meliputi grip, block kohs, sisip ring, form, puzzle, dan format penilaian".

Pada saat pengukuran IQ, tidak semua anak yang mendaftar di Barehsos "Disgranda" Sragen diterima. Anak dengan kategori bodoh tidak diterima karena mereka masih bisa dididik di sekolah formal.Langkah selanjutnya bagi anak yang diterima adalah dengan memantapkan penempatan kelompok vokasional, dimana mereka di evaluasi oleh para pekerja sosial berdasarkan hasil tes anak.Penempatan harus sesuai dengan kategori anak karena teknik yang diberikan berbeda-beda. 


\section{Pelaksanaan Penerapan Nilai-nilai Akhlak Melalui Pendidikan Vokasional}

Pelaksanaan bimbingan activity daily living (ADL) yang diberikan antara lain perawatan diri mulai dari mandi, gosok gigi, merapikan selimut, sprei, sholat, kebersihan lingkungan, makan, apel pagi, dan kedisiplinan.

Kegiatan tersebut dilaksanakan setiap hari senin, para pembimbing mengawasi kelompok anaknya masing-masing. Pertama-tama pembimbing mengajari anak mulai dari bangun tidur untuk merapikan bantal, sprei dan selimut.Langkah selanjutnya anak-anak diajari mandi, cuci, kakus (MCK), dan gosok gigi yang benar. Langkah berlanjut ke makan, dimana anak diajari untuk cara makan yang benar, dengan memperkenalkan kegunaan sendok, garpu, piring, gelas serta cara memcuci piring yang baik dan bersih.

Perencanaan dan pelaksanaan proses pendidikan maupun bimbingan, perlu adanya evaluasi untuk mengukur tingkat keberhasilan yang diperoleh, guna untuk melengkapi setiap kekurangan yang ada. Pembimbingan dilakukan atas dasar rasa cinta dan peduli.Mereka memiliki harapan anak-anak tuna grahita yang mereka bimbing memiliki prestasi dan bisa diterima masyarakat sebagaimana anak normal pada umumnya.Biarpun pada kenyataanya secara fisik mereka berbeda, tetapi secara keterampilan mereka sudah layak.

Pertemuan dengan wali murid dilakukan setiap satu bulan sekali, dengan tujuan untuk memperkenalkan hasil karya maupun perkembangan anak., baik dari segi mental, sosial maupun keterampilan, dan kemandirian ADL. Sehingga suatu saat anak kembali ke rumah, orang tua bisa mengarahkan dan memahami kebutuhan anak, perilaku anak bisa terkontrol saat bergaul dengan orang lain yang ada dirumah. Kedisiplinan yang diajarkan akan menjadi suatu kebiasaan yang baik tanpa harus selalu disuruhsuruh. 
Evaluasi dari pembimbing itu sendiri juga dilakukan setiap dua bulan sekali.Evaluasi tersebut berupa laporan dari pembimbing maupun wali kelas.Dan pertanggungjawaban di pusat dilakukan setiap satu tahun sekali.Beradasarkan data yang diketahui, sebagaimana penulis sajikan pada fakta temuan penelitian diatas, maka langkah selanjutnya yaitu menganalisis data-data yang terkumpul dengan menggunakan metode deskriptif kualitatif.

Keberadaan guru dalam membimbing memiliki tugas dan tanggung jawab yang besar. Dimana tugas tersebut tidak dapat diambil alih oleh pekerja lain. Mendidik yang utama adalah membentuk akhlak anak, dikarenakan keterbatasan IQ anak tuna grahita maka cara membentuk akhlak tersebut yang paling efektif di Barehsos "Disgranda" Sragen adalah melalui pendidikan vokasional berupa keterampilan psikomotorik. Meskipun menyandang sebagai anak tunagrahita, mereka tetap memiliki kesempatan melangsungkan kehidupannya, maka pemberian bekal keterampilan sangat diperlukan.

Dari hasil temuan di lapangan yang digali melalui observasi, wawancara maupun dokumentasi maka dapat disampaikan analisis data sebagai berikut:

a. Pelaksanaan Pendidikan Vokasional

Pendidikan vokasional di balai diampu oleh pembimbing sesuai dengan keahliannya. Setelah anak diterima dan masuk dalam kelompok vokasional, selanjutnya akan mendapatkan wali kelas yang mendampingi sampai anak lulus.

Upaya guru dalam memberikan keterampilan yang meliputi activity daily living(ADL) diperoleh akhlak kemandirian, tanggung jawab, disiplin dan kerjasama.Dimulai dari disiplin waktu, disiplin shoal, disiplin makan dan kerapian. Kedisiplinan tersebut akan berpengaruh pada kebiasaan baik anak. Ketika seseorang bisa mengalahkan ego dan lebih mementingkan perasaan, maka untuk membentuk tingkah dan perilaku akan lebih mudah. Dimana 


\section{Chamim Tohari}

ditanamkan bahwa manusia adalah makhluk sosial yang tidak bisa hidup sendiri, tetapi bukan berarti selalu membutuhkan bantuan orang lain. Ini akan menjadi bekal manusia bisa menjadi makhluk yang berakhlak. Biarpun memiliki kekurangan, hati nurani mereka berjalan sebagaimana manusia normal.

b. Cara Penerapan Nilai-nilai Akhlak Anak

Tersedianya sarana dan prasarana maka bimbingan keterampilan di Balai dilaksanakan sesuai jadwal.Bimbingan tidak terlepas dari metode pembelajaran. Pertama kali yang dilakukan menyadarkan anak bahwa tidak boleh membebani orang lain. Mengajak anak untuk tidak malas dengan selalu member motivasi kepada anak.Mencoba melakukan kegiatan sendiri tanpa disuruh. Anak mandiri untuk makan, mandi, merapikan tempat tidur dan lain-lain. Dengan demikian akan timbul rasa tolong menolong kepada teman yang berat tidak mampu melakukan apa-apa.

Guru sebagai fasilitator serta motivator memang sangat menunjang keberhasilan anak. Metode yang digunakan adalah:

1) Metode contoh dengan mempraktikan langsung sambil diarahkan. Menjelaskan kepada anak dengan gambar maupun bermain peran.

2) Metode pembiasaan, anak dibiasakan untuk datang tepat waktu, masuk ruang jam 08.00 ketika berlatih, itu akan membiasakan anak untuk bertanggung jawab terhadap tugasnya.

3) Metode pengawasan, pembimbing selalu mendampingi anak dalam setiap latihan, anak diberi buku catatan tersendiri dengan format tanggal, nama, alamat, dan keterangan.

4) Metode nasihat dan peringatan.

5) Metode hadiah dan hukuman, memberikan motivasi kepada setiap anak yang malas dalam setiap latihan. Bagi anak yang rajin latihan dan menaati peraturan di balai akan dipamerkan ke teman-teman yang lain, sehingga itu 
akan menjadi suatu kebanggan tersendiri bagi anak, dan sekaligus memotivasi anak yang lain.

\section{Simpulan}

Pelaksanan penerapan nilai-nilai akhlak melalui pendidikan vokasional di Barehsos Disgranda "Rharjo" Sragen diantaranya adalah bimbingan activity daily living(ADL).Banyak metode yang digunakan dalam pelaksanaanya.Penggunaan metode tersebut disesuaikan dengan kebutuhan anak dan kondisi yang dihadapi.Penggunaan sarana dan prasarana yang menunjang, lengkap, mudah dimengerti dan dapat mengantarkan anak pada keberhasilan berinteraksi sosial.Tahap dalam mendidik berawal dari keteladanan guru/pembimbing, dan kemauan dari anak untuk bisa menjadi lebih baik dan berhasil kehidupannya kelak. Metode pembiasaan yang sering diulang-ulang akan memudahkan anak untuk mengingat apa yang telah diajarkan pembimbing. Metode nasihat untuk mengarahkan.Metode pengawasan baik secara langsung maupun tidak langsung.Serta metode pemberian hadiah serta hukuman untuk meningkatkan motivasi anak adalam pembentukan akhlak kepada diri sendiri.

Akhlak yang dibentuk adalah akhlak kepada diri sendiri bagi anak tunagrahita yang berupa kemandirian hidup, tanggung jawab terhadap kelangsungan hidupnya dengan berbekal keterampilan, disiplin dalam setiap kegiatan, kerjasama, mampu berinteraksi sosial dengan lingkungan. 


\section{DAFTAR PUSTAKA}

Amirin, Tatang M.,Menyusun Rencana Penelitian, Jakarta: Raja Grafindo Persada, 1990

Al-Ghazali,Ihya' Ulumuddin Jilid IV.Faisan : Jakarta Selatan,1989

Dinata,Nana Syaudih Sukma,Metodologi Penelitian Pendidikan, Bandung: PT Remaja Rosda Karya, 2004

Efendi,Mohammad,Pengantar Psikopedagogik Anak Berkelainan, Jakarta: PT Bumi Aksara, 2006

Ilyas,Yunahar, Kuliah Akblak. Yogyakarta : Pustaka Pelajar Offset,1999

Illahi,M. Takdir,Pembelajaran Discovery Strategy \& Mental Vocational Skill.Yogyakarta : Diva Press, 2012

Khalid, Amru,Semulia Akblak Nabi. Solo : Aqwam, 2006

Moleong,Lexy J., Metodologi Penelitian Kualitatif, Bandung: PT Remaja Rosda Karya, 2005

Muhaimin, dkk, Studi Islam dalam Ragam Dimensi dan Pendekatan. Jakarta : Kencana Prenada Media Group, 2005

Mumpuniarti,Pendekatan Pembelajaran Bagi Anak Hambatan Mental, Yogyakarta: Kanwa Publisher, 2007

Nata,Abuddin, Akblak Tasawnf. Jakarta : Rajawali Pers, 2012

Narko, Cholid \& Achmadi,Abu,Metodologi Penelitian, Jakarta: PT Bumi Aksara, 2005

Somantri,H.T. Sutjihati, Psikologi Anak Luar Biasa, DEPDIKBUD:

Dirjen Pendidikan Tinggi Proyek Pendidikan Tenaga Guru, 1996

Remaja Rosdakarya, 2004

Sukarjo, M., \&Komarudin,Ukim,Landasan Pendidikan Konsep dan Aplikasinya, Jakarta: Rajawali Pers, 2009

TIM Penyusun. 2004. Panduan Penulisan Skripsi, Yogyakarta: Jurusan PAI Fakultas Tarbiyah UIN Sunan Kalijaga Yogyakarta

Zuhairini, Filsafat Pendidikan Islam, Jakarta: Bumi Aksara,1992 